\title{
Retroperitoneal Extragastrointestinal Stromal Tumors Have a Poor Survival Outcome: A Multicenter Observational Study
}

This article was published in the following Dove Press journal: Cancer Management and Research

\begin{abstract}
Weixian $\mathrm{Hu}$, iD $^{1}{ }^{\mathrm{*}} *$ Chengbin Zheng, ${ }^{1}, *$ Renjie $\mathrm{Li}^{2}{ }^{2}$ Xingyu Feng,' Guoliang Zheng, Zhichao Zheng, ${ }^{3}$ Wenjun Xiong, Guosheng Lin, ${ }^{5}$ Yongjian Zhou, Wei Wang, ${ }^{4}$ Yan Zhao, iD ${ }^{3}$ Yong $\mathrm{Li}^{\mathrm{I}}$

'Department of General Surgery, Guangdong Provincial People's Hospital, Guangdong Academy of Medical Sciences, Guangzhou, Guangdong 510080, People's Republic of China; ${ }^{2}$ Department of Bariatric and Metabolic Surgery, Klinikum Ernst von Bergmann, Potsdam I4467, Germany; ${ }^{3}$ Department of Gastric Cancer, Cancer Hospital of China Medical University, Liaoning Cancer Hospital and Institute, Shenyang, Liaoning I 10042, People's Republic of China; ${ }^{4}$ Department of Gastrointestinal Surgery, Guangdong Provincial Hospital of Chinese Medicine, The Second Affiliated Hospital of Guangzhou University of Chinese Medicine, Guangzhou 510120, People's Republic of China; ${ }^{5}$ Department of Gastric Surgery, Fujian Medical University Union Hospital, Fuzhou, Fujian 35000I, People's Republic of China
\end{abstract}

*These authors contributed equally to this work.

Correspondence: Yong Li

Department of General Surgery, Guangdong Provincial People's Hospital; Guangdong

Academy of Medical Sciences, 106

Zhongshan Road 2, Guangzhou, Guangdong

510080 , People's Republic of China

Tel +86-13822I77479

Fax +86-838278I2

Email liyong@gdph.org.cn

Yan Zhao

Department of Gastric Cancer, Cancer Hospital of China Medical University, Liaoning Cancer Hospital and Institute,

Shenyang, Liaoning 1 10042, People's

Republic of China

Tel +86-189009|8909

Email zhaoyan@CancerHosp-LN-CMU. com
Purpose: Gastrointestinal stromal tumors (GISTs) are commonly known to be derived from the gastrointestinal (GI) tract, but recently there have been more and more literature describing lesions with similar pathological and immunohistochemical resembling GISTs but located outside the GI tract, and they have been termed as extra-GISTs (eGISTs). However, due to the rare incidence of eGISTs, its association with survival outcomes is poorly understood, especially in the Chinese population. Here, we aimed to identify the risk factors of eGISTs and to assess their association with overall survival (OS) and disease-free survival (DFS).

Patients and Methods: Data of pathologically confirmed eGISTs cases, without radiological and perioperative evidence of other primary lesions, and with no microscopically identified adhesion between the tumor and the gastrointestinal serosa, which were surgically treated between January 2006 and September 2017 were retrieved from the database of four high-volume hospitals. Immunohistochemical and genetic testing were performed on the postoperative lesions and were staged using the National Institutes of Health (NIH) criteria. Results: A total of 55 cases were retrieved. eGISTs were identified from the retroperitoneum (36.4\%), mesocolon (25.5\%), small bowel mesentery (12.7\%), abdominopelvic cavity $(12.7 \%)$, lesser omental sac $(5.5 \%)$, ovary $(3.6 \%)$, pancreatic capsule $(1.8 \%)$, or urinary bladder (1.8\%). Based on the NIH risk classification, majority of the lesion were classified as high risk $(85.5 \%)$. KIT 11 was the most common mutation site $(76.5 \%)$ and $25.0 \%$ of the cases were wild-type eGISTs. Multivariate analyses showed that tumor location and size were independent factors affecting prognoses. Patients with tumors in the retroperitoneum had significantly poorer OS and DFS as compared to those in the non-retroperitoneum (HR [95\% CI] for OS and DFS: $2.546[1.023-6.337][P=0.037]$ and $2.475[0.975-6.273][P=$ 0.049], respectively). Similar findings were found for tumors of size $>15 \mathrm{~cm}$, compared to $\leq 15 \mathrm{~cm}$ (HR [95\% CI] for OS and DFS: 5.350 [2.022-14.156] $[P<0.001]$ and 3.861 [1.493-9.988] [P=0.003], respectively).

Conclusion: eGISTs were predominantly found from the retroperitoneum and mostly classified as high risk. Those located in the retroperitoneum and of size $>15 \mathrm{~cm}$ had the poorer OS and DFS as compared to those in the non-retroperitoneum and of size $<15 \mathrm{~cm}$.

Keywords: extra gastrointestinal stromal tumors, multicenter, immunohistopathology, gene mutation, National Institutes of Health criteria, risk factor, retroperitoneum, overall survival, disease-free survival, recurrence

\section{Introduction}

Gastrointestinal stromal tumors (GISTs) are the most common digestive tract mesenchymal neoplasms worldwide with an incidence rate of 10-15 cases 
per million people per year. ${ }^{1}$ GISTs are traditionally considered to originate from the interstitial cells of Cajal (ICC) of the myenteric plexus. ${ }^{2,3}$ Preoperatively, they are identified on radiological imaging (contrast computed tomography $[\mathrm{CT}]$ or magnetic resonance imaging $[\mathrm{MRI}]$ ) but are also commonly diagnosed postoperatively by pathological and immunohistological examinations, characterized by their spindle, epithelioid and/or polymorphic cells, and positive staining to the CD117 (c-kit receptor) and CD34 biomarkers. Current studies have found that the activated gain-of-function mutations of receptor tyrosine kinase KIT proto-oncogene or platelet-derived growth factor receptor alpha (PDGFRA) gene drive the occurrence of GISTs. ${ }^{4,5}$ GISTs may occur anywhere in the gastrointestinal tract; from the esophagus to the anorectum. Their most frequent incident anatomic sites are the stomach $(\sim 60 \%)^{6-9}$ and small intestine $(\sim 35 \%),{ }^{6-9}$ and less frequently found in the colorectum (5\%-6\%) ${ }^{6-9}$ and esophagus $(\sim 1 \%))^{7,9}$

Although GISTs have been initially considered to arise mainly from the gastrointestinal tract; however, an increasing amount of literature is identifying tumors mimicking GISTs but located outside the GI tract and bearing similar immunohistological, pathological and molecular characteristics. Scholars have suggested that stromal tumors may originate from the mesodermal mesenchymal stem cells, which have pluripotent differentiation ability and can differentiate into a variety of mesodermal tissues, including the Cajal cells. ${ }^{10}$ It is also hypothesized that under the action of external force or other factors from its site of origin, namely the outermost muscle fibers of the digestive tract, the tumor then leaves the digestive tract wall and grows outside of the digestive tract, thereby forming extracavitary GIST. In 1999, a report of 26 cases originating from the omentum and the mesentery and showed that their clinicopathological and immunohistochemical features were similar to that of GISTs. ${ }^{11}$ Since then, they have been termed as extragastrointestinal stromal tumors (eGISTs).

There have been few large cohort studies to investigate the prognosis of eGIST based on its different sites of occurrence. Miettinen et al retrospectively analyzed 112 cases of eGISTs arising from the retroperitoneum in the pre-imatinib era (from the year 1970 to 1996). They found that the prognoses of retroperitoneal eGISTs $(n=79)$ were poor and had a median survival of only 14 months. ${ }^{12}$ However, some scholars believe that the biological characteristics of eGISTs resemble that of GISTs arising from the distal digestive tract. ${ }^{13}$ Another study showed that eGISTs derived from the omentum, whose tumor cells are rarely epithelial cells, possessed similarities to gastric GISTs and had better prognosis compared to eGISTs arising from other locations. In contrast, eGISTs occurring in the mesentery were found to have morphologies and biological characteristics similar to those of small intestinal GISTs but with comparatively poorer prognosis. ${ }^{14}$

Till present, most of the eGISTs reported were large $(>10 \mathrm{~cm})$ or had high mitotic counts $(>10 / 50$ high-power field $[\mathrm{HPF}])$ and thereby classified as high-risk cases. ${ }^{18}$ Moreover, due to their rare incidence large studies $(N>50)$ on eGISTs are limited, and their histogenesis and clinicopathological features related to prognosis are poorly understood. Here, we analyzed a multicentered database from high-volume hospitals to assess the clinicopathological features of eGISTs originating from different extragastrointestinal tract sites and their association with survival outcomes.

\section{Patients and Methods \\ Patient Selection}

We retrospectively retrieved the data of consecutive adult patients histopathologically diagnosed as unknown primary origin eGISTs between January 2006 and September 2017 at the Guangdong Provincial People's Hospital, Liaoning Cancer Hospital \& Institute, Guangdong Province Traditional Medical Hospital and Fujian Medical University Union Hospital. The data comprised patient demographics, clinical presentation, surgery, histopathology, postoperative course, and oncologic outcomes. For patients with missing information, they were contacted by email exchanges or phone calls from their respective treating hospitals.

The criteria for inclusion in this study were: (1) pathologically confirmed diagnosis of eGISTs, (2) without radiological and perioperative evidence of other primary lesions, (3) underwent surgical treatment, and (4) had no record of surgical laparotomy of the entire abdomen for other lesions. The exclusion criteria were: (1) microscopically identified adhesion between the tumor and the gastrointestinal serosa, (2) prior history of GISTs/eGISTs, (3) the presence of other malignancies, and (4) death caused by other diseases. The patient selection process is illustrated as a flow chart in Figure 1.

\section{Clinicopathology and Surgery}

Clinicopathological data included the patient's age, gender, the presence or absence of tumor necrosis and necrosis, tumor site, tumor size, mitotic counts, histopathological 


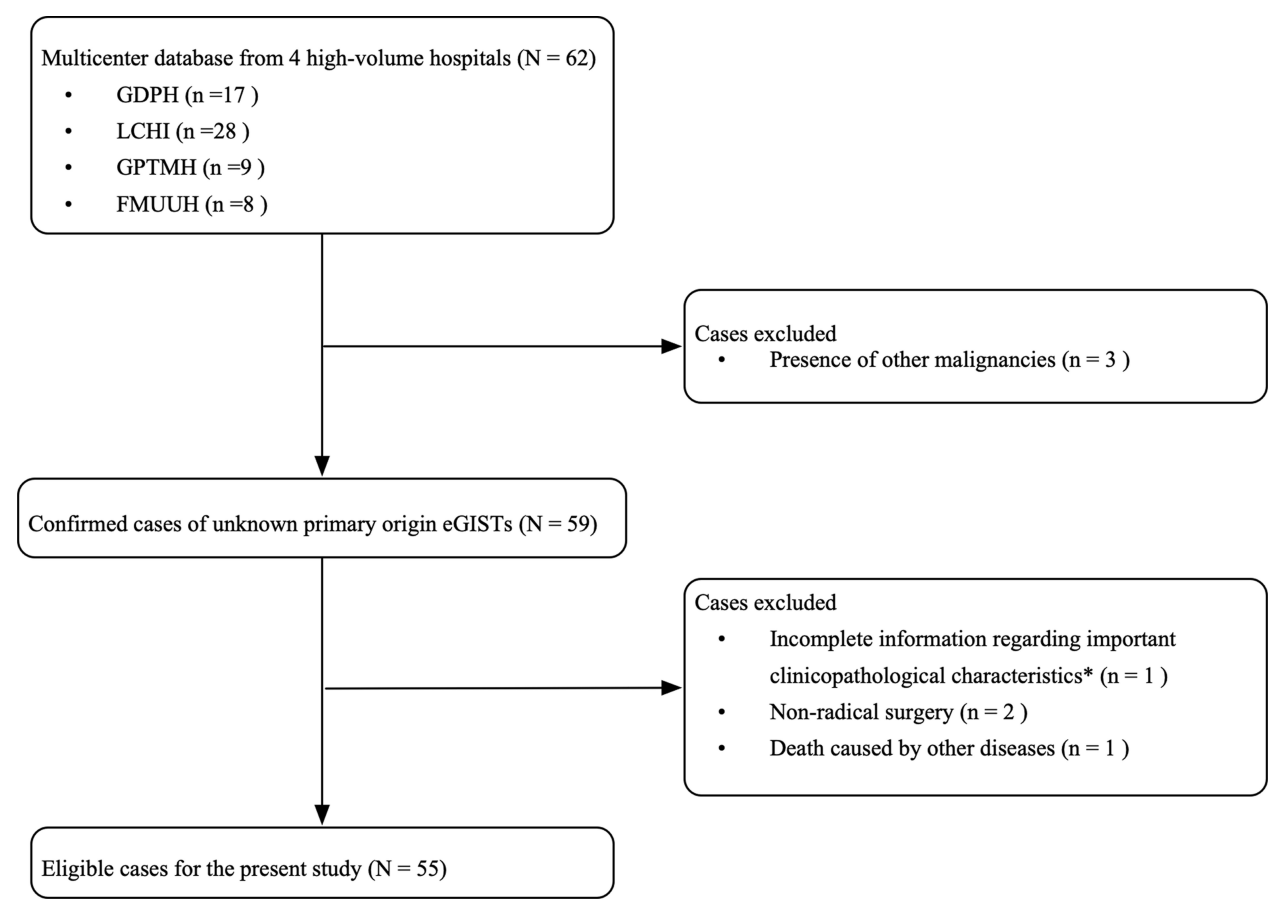

Figure I Study flowchart of the patient data retrieval process. *refers to characteristics such as age, gender, tumor size, tumor location, incomplete histopathological report.

Abbreviations: GDPH, Guangdong Province People's Hospital; LCHI, Liaoning Cancer Hospital \& Institute; GPTMH, Guangdong Province Traditional Medical Hospital; FMUUH, Fujian Medical University Union Hospital; eGISTs, extragastrointestinal stromal tumors.

classification, postoperative complications, and adjuvant therapy. The eGISTs surgical resection was performed by surgeons having $>10$-year experience in GI surgeries. Before and after resection of the tumor, the abdomen of the patients was carefully inspected for the presence of additional lesions, and if present, were sent for pathological examinations. The resected specimens were formalin-fixed in paraffin-embedded blocks for sectioning and were stained with hematoxylin and eosin (H\&E). Immunohistopathology was performed by skilled pathologists. The main immunohistochemical markers were CD117, CD34 and DOG-1. Briefly, the intensity of staining was scored as negative (-), weak $(+)$, moderate $(++)$, or strong $(+++)$. Any signal was considered to be positive. For gene testing, the patients' DNA were independently extracted from the formalinfixed tissues, and amplification using polymerase chain reaction and direct sequencing were performed for selected mutation hotspots in the KIT exons 9, 11, 13, and 17, and PDGFRA exons 12, 14, and 18. The risk of recurrence was evaluated according to the National Institutes of Health (NIH) criteria into a very low-, low-, intermediate-, or highrisk groups. ${ }^{15,16}$ Tumors with fewer than 5 mitoses per 50 high-power fields (HPF, $400 \times$ magnification level) and diameter less than $2 \mathrm{~cm}$ have very low-risk lesion. Low-risk lesions include those tumors with fewer than 5 mitoses per $5 / 50 \mathrm{HPF}$, and measuring less than $5 \mathrm{~cm}$. Intermediate-risk lesions are those less than $5 \mathrm{~cm}$ in size with 6 to 10 mitoses and those measuring 5 to $10 \mathrm{~cm}$ with fewer than 5 mitoses. High-risk lesions are larger than $5 \mathrm{~cm}$ with more than 5 mitoses and all lesions greater than $10 \mathrm{~cm}$ or with more than 10 mitoses.

\section{Follow-Up}

Follow-up was carried out by outpatient surveillance or telephone calls. The outpatient postoperative follow-up included clinical, laboratory examinations and computed tomography scanning, performed every 3 months for the first 2 years, every 6 months from the 3rd to 5th years, every 12 months thereafter or earlier as deemed necessary by the patients' treating physician based on their conditions. The main objective of the present study was to identify the risk factors affecting the survival outcomes of patients with eGIST. Survival outcomes were based on the patients' overall survival (OS), calculated from the date of surgery to the last follow-up date (May 31, 2018) or death, and diseasefree survival (DFS), calculated from the date of surgery to disease recurrence. Disease recurrence was determined based on radiological (CT/MRI) evidence. 


\section{Statistical Analysis}

Statistical analyses were performed using the SPSS software, version 25.0 (SPSS, Chicago, IL, USA). The Student $t$ test or Mann-Whitney test was used for intergroup comparisons of continuous variables, and the $\chi^{2}$ or Fisher test was used to compare categorical data. Survival analyses were computed using the Kaplan-Meier method and the Log rank test. Univariate analyses and multivariate Cox proportional hazard regression were performed to identify prognostic variables related to survival outcomes. Adjusted hazard ratios (HR) along with their corresponding 95\% confidence intervals $(\mathrm{CI})$ were also calculated. A difference in $P$ values $<0.05$ was considered as having statistical significance.

Further, an exact test was performed to supplement the initial analyses whereby potential risk factors for adverse events had been identified. This test assessed the difference in incidence rates of adverse events between individuals who had none, one or two potential risk factors.

\section{Results}

\section{Clinicopathological Features of eGISTs}

A total of 55 cases diagnosed as eGISTs fit the inclusion criteria, from which $20(36.4 \%)$ were found to be located in the retroperitoneum, $14(25.5 \%)$ in the mesocolon, $7(12.7 \%)$ in the small bowel mesentery, $7(12.7 \%)$ in the abdominopelvic cavity, $3(5.5 \%)$ in the lesser omental sac, $2(3.6 \%)$ in the ovary, $1(1.8 \%)$ in the pancreatic capsule and $1(1.8 \%)$ in the urinary bladder (Figure 2). Of note, for the patients included in this study, no other lesions apart from the eGIST were discovered pre- and perioperatively both after careful inspection of the patients' radiological imaging and explorative laparotomy.

Data of the patients' clinicopathological features are illustrated in Table 1. There were 31 (56.4\%) men and $24(43.6 \%)$ women, of an average age ( \pm standard deviation [S.D]) of $58( \pm 13.87)$ years and a median age of 58 (range, 29-90 years) years old. Their postoperative median tumor size was 13 (range, $0.4-29.0 \mathrm{~cm}$ ) $\mathrm{cm}$ and a considerable proportion of tumors were $>15 \mathrm{~cm}$ (36.4\%) while only $12.8 \%$ were $\leq 5 \mathrm{~cm}$. Most of the cases were of spindle histopathology (76.4\%). Based on the modified NIH risk classification, the number of cases classified as very low-, low-, intermediate-, and high-risk groups were 3.6\%, 5.5\%, $5.5 \%$, and $85.5 \%$, respectively.

\section{Immunohistochemistry and Gene Mutation Characteristics of eGISTs}

The immunohistochemistry and gene mutation examination features are shown in Table 2. All investigated patients were postoperatively pathologically tested for CD117 and CD34 with positive recorded rates of $78.2 \%$ and $70.9 \%$. Thirty-seven patients were tested for DOG-1, with a positive rate of $37.8 \%$. Among the 24 patients who underwent genetic testing, KIT 11 was the most common mutation site with a mutation rate of $76.5 \%(13 / 17)$. Patients with wild-type eGISTs accounted for $25.0 \%$ of the examined cases. Due to the limited number of cases
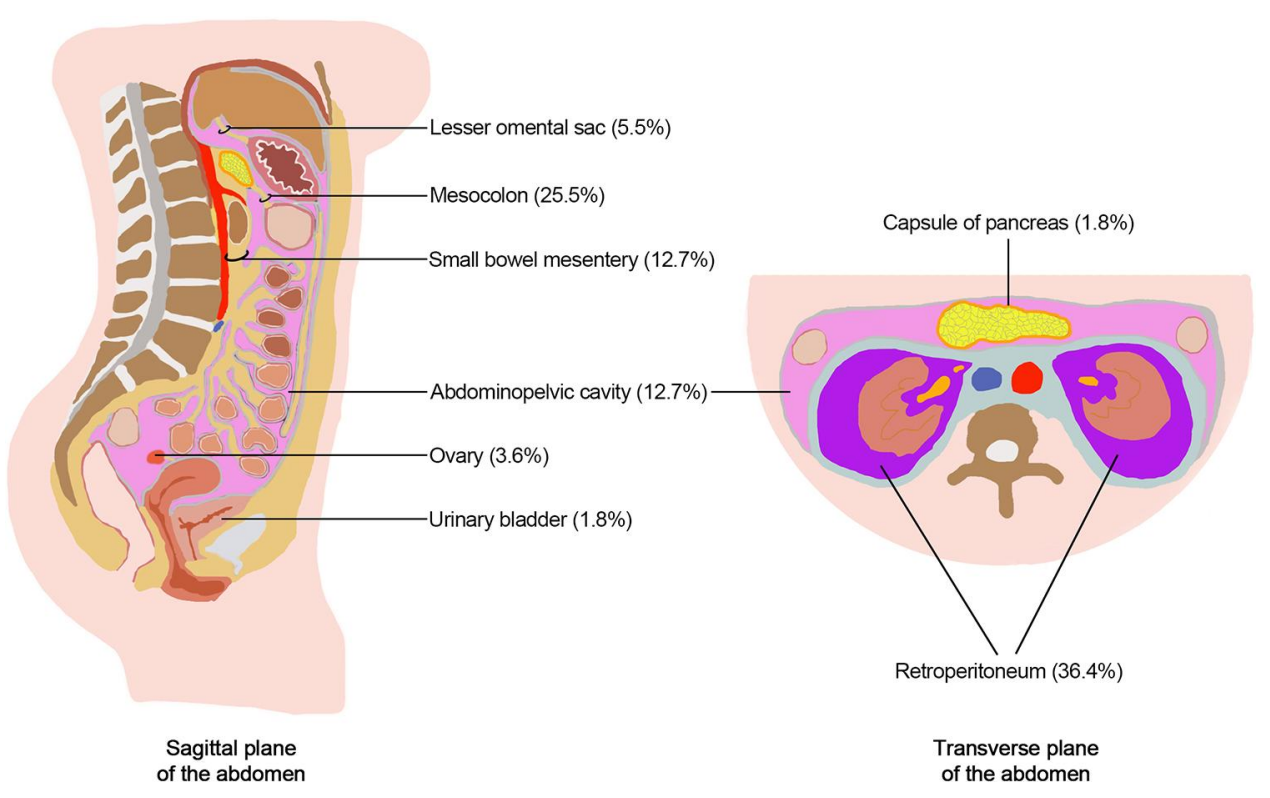

Figure 2 Anatomic distribution of eGISTs in a (A) sagittal and (B) transverse plane of the abdomen. Abbreviation: eGISTs, extragastrointestinal stromal tumors. 
Table I Association of Clinicopathological Characteristics of eGIST Patients with OS and DFS

\begin{tabular}{|c|c|c|c|c|c|}
\hline \multirow[t]{2}{*}{ Characteristics } & \multirow[t]{2}{*}{ n (\%) } & \multicolumn{2}{|c|}{ OS ( $P$ value) } & \multicolumn{2}{|c|}{ DFS ( $P$ value) } \\
\hline & & $\begin{array}{l}\text { Univariate } \\
\text { Analysis }\end{array}$ & $\begin{array}{l}\text { Multivariate } \\
\text { Analysis }\end{array}$ & $\begin{array}{l}\text { Univariate } \\
\text { Analysis }\end{array}$ & $\begin{array}{l}\text { Multivariate } \\
\text { Analysis }\end{array}$ \\
\hline $\begin{array}{l}\text { Age(year) } \\
\quad \leq 58 \\
>58\end{array}$ & $\begin{array}{l}28(50.9) \\
27(49.1)\end{array}$ & 0.027 & 0.200 & 0.161 & \\
\hline $\begin{array}{l}\text { Gender } \\
\text { Male } \\
\text { Female }\end{array}$ & $\begin{array}{l}31(56.4) \\
24(43.6)\end{array}$ & 0.951 & & 0.862 & \\
\hline $\begin{array}{l}\text { Tumor rupture } \\
\text { Present } \\
\text { Absent }\end{array}$ & $\begin{array}{l}2(3.6) \\
53(96.4)\end{array}$ & 0.182 & & 0.660 & \\
\hline $\begin{array}{l}\text { Tumor necrosis } \\
\text { Present } \\
\text { Absent }\end{array}$ & $\begin{array}{l}33(60.0) \\
22(40.0)\end{array}$ & 0.109 & & 0.310 & \\
\hline $\begin{array}{l}\text { Tumor location (overall) } \\
\text { Retroperitoneum } \\
\text { Mesocolon } \\
\text { Small bowel mesentery } \\
\text { Abdominopelvic cavity } \\
\text { Lesser omental sac } \\
\text { Ovary } \\
\text { Capsule of pancreas } \\
\text { Bladder }\end{array}$ & $\begin{array}{l}20(36.4) \\
14(25.5) \\
7(12.7) \\
7(12.7) \\
3(5.5) \\
2(3.6) \\
1(1.8) \\
1(1.8)\end{array}$ & 0.002 & & 0.010 & \\
\hline $\begin{array}{l}\text { Tumor location (categorized) } \\
\text { Retroperitoneum } \\
\text { Non-retroperitoneum }\end{array}$ & $\begin{array}{l}20(36.4) \\
35(63.6)\end{array}$ & 0.037 & 0.048 & 0.0490 & 0.044 \\
\hline $\begin{array}{l}\text { Tumor size } \\
\begin{array}{l}\text { (4 categories) }(\mathrm{cm}) \\
\leq 5 \\
>5-\leq 10 \\
>10-\leq 15 \\
>15\end{array}\end{array}$ & $\begin{array}{l}7(12.7) \\
16(29.1) \\
12(21.8) \\
20(36.4)\end{array}$ & 0.002 & & 0.028 & \\
\hline $\begin{array}{l}\text { Tumor size } \\
\text { ( } 2 \text { categories) }(\mathrm{cm}) \\
\leq 15 \\
>15\end{array}$ & $\begin{array}{l}35(63.6) \\
20(36.4)\end{array}$ & $<0.001$ & 0.020 & 0.003 & 0.010 \\
\hline $\begin{array}{l}\text { Mitotic count (150 HPF) } \\
\quad \leq 5 \\
>5-\leq 10 \\
>10\end{array}$ & $\begin{array}{l}26(47.3) \\
12(21.8) \\
17(30.9)\end{array}$ & 0.051 & & 0.056 & \\
\hline $\begin{array}{l}\text { Mitotic count (/50 HPF) } \\
\leq 5 \\
>5\end{array}$ & $\begin{array}{l}26(47.3) \\
29(52.7)\end{array}$ & 0.035 & 0.253 & 0.017 & 0.465 \\
\hline $\begin{array}{l}\text { Histopathological classification } \\
\text { Spindle } \\
\text { Epithelioid } \\
\text { Mixed }\end{array}$ & $\begin{array}{l}42(76.4) \\
\text { I (1.8) } \\
12(21.8)\end{array}$ & 0.226 & & 0.601 & \\
\hline
\end{tabular}

(Continued) 
Table I (Continued).

\begin{tabular}{|c|c|c|c|c|c|}
\hline \multirow[t]{2}{*}{ Characteristics } & \multirow[t]{2}{*}{ n (\%) } & \multicolumn{2}{|c|}{ OS ( $P$ value) } & \multicolumn{2}{|c|}{ DFS ( $P$ value) } \\
\hline & & $\begin{array}{l}\text { Univariate } \\
\text { Analysis }\end{array}$ & $\begin{array}{l}\text { Multivariate } \\
\text { Analysis }\end{array}$ & $\begin{array}{l}\text { Univariate } \\
\text { Analysis }\end{array}$ & $\begin{array}{l}\text { Multivariate } \\
\text { Analysis }\end{array}$ \\
\hline $\begin{array}{l}\text { Postoperative complications } \\
\text { Present } \\
\text { Absent }\end{array}$ & $\begin{array}{l}4(7.3) \\
51(92.7)\end{array}$ & 0.028 & & 0.229 & \\
\hline $\begin{array}{l}\text { Adjuvant therapy } \\
\text { Received } \\
\text { Not received }\end{array}$ & $\begin{array}{l}20(36.4) \\
35(63.6)\end{array}$ & 0.797 & & 0.827 & \\
\hline $\begin{array}{l}\text { Modified NIH risk categories } \\
\text { VLR } \\
\text { LR } \\
\text { IR } \\
\text { HR }\end{array}$ & $\begin{array}{l}2(3.6) \\
3(5.5) \\
3(5.5) \\
47(85.5)\end{array}$ & 0.376 & & 0.378 & \\
\hline
\end{tabular}

Abbreviations: eGISTs, extragastrointestinal stromal tumors; HPF, high-power field; VLR, very low risk; LR, low risk; IR, intermediate risk; HR, high risk.

that received adjuvant imatinib and considering that the patient's willingness for long-term therapy was low, an association between adjuvant imatinib therapy, immunohistochemistry and gene mutation could not be analyzed.

\section{Association of eGIST Patients' Clinicopathological Features to Survival Outcomes}

To investigate the prognostic factors of eGISTs to survival, the clinicopathological features listed in Table 1 were

Table 2 Immunohistochemistry and Gene Mutation Examination Features of the eGIST Patients

\begin{tabular}{|l|l|l|}
\hline $\begin{array}{l}\text { Pathological } \\
\text { Examination }\end{array}$ & $\begin{array}{l}\text { No. of Patients } \\
\text { (n) }\end{array}$ & $\begin{array}{l}\text { No. Positive } \\
\text { Cases (\%) }\end{array}$ \\
\hline $\begin{array}{l}\text { Immunohistochemistry } \\
\text { CDII7 }\end{array}$ & 55 & $43(78.2)$ \\
CD34 & 55 & $39(70.9)$ \\
DOG-I & 37 & $23(62.2)$ \\
\hline Gene test & & \\
KIT 9 & 6 & $2(33.3)$ \\
KIT II & 17 & $13(76.5)$ \\
KIT I3 & 4 & $0(0.0)$ \\
KIT I7 & 4 & $0(0.0)$ \\
PDGFRA I2 & 5 & $1(20.0)$ \\
PDGFRA /4 & 4 & $0(0.0)$ \\
PDGFRA I8 & 6 & $2(33.3)$ \\
Wild type & 24 & $6(25.0)$ \\
None detected & $3 I$ & $3 I(56.4)$ \\
\hline
\end{tabular}

Abbreviations: eGISTs, extragastrointestinal stromal tumors; PDGFRA, plateletderived growth factor receptor alpha. evaluated using univariate and multivariate analyses. Tumor locations and size were grouped into two main subgroups, namely, the retroperitoneum or nonretroperitoneum, and $\leq 15$ or $>15 \mathrm{~cm}$, respectively, and were used in the multivariate analyses.

For a median follow-up time of 36.2 (range: 1.45-112.1 months) months, our findings showed that both tumor locations and size were independent prognostic factors for OS and DFS. Patients with tumors located in the retroperitoneum had significantly poorer OS and DFS as compared to those in the non-retroperitoneum (HR $[95 \% \mathrm{CI}]$ for OS and DFS: 2.546 [1.023-6.337] $[P=0.037]$ and 2.475 [0.975-6.273] [ $P=0.049]$, respectively; Figure 3A and B). Similarly, those with tumors of size $>15 \mathrm{~cm}$ had significantly poorer OS and DFS compared to those of tumors $\leq 15 \mathrm{~cm} \quad$ (HR $[95 \% \mathrm{CI}]$ for OS and DFS: 5.350 [2.022-14.156] $[P<0.001]$ and 3.861 [1.493-9.988] $[P=$ 0.003 ], respectively; Figure $3 \mathrm{C}$ and D).

Next, we investigated the relationship between the incidence of these adverse prognostic factors to tumor-related death and recurrence. The incidence of adverse outcomes per person-year (computational formula: no. of adverse event/ total follow-up years) in the group without adverse factors, with one adverse factor, and with two adverse factors were $0.02,0.10$, and 0.35 for tumor-related death, and were 0.04 , 0.11 and 0.49 for recurrence, respectively. As shown in Table 3, patients with both risk factors (retroperitoneumlocated eGISTs with size $>15 \mathrm{~cm}$ ) had a greater risk of disease recurrence and death as compared to those with none $(P=0.008$ and $<0.001)$. 

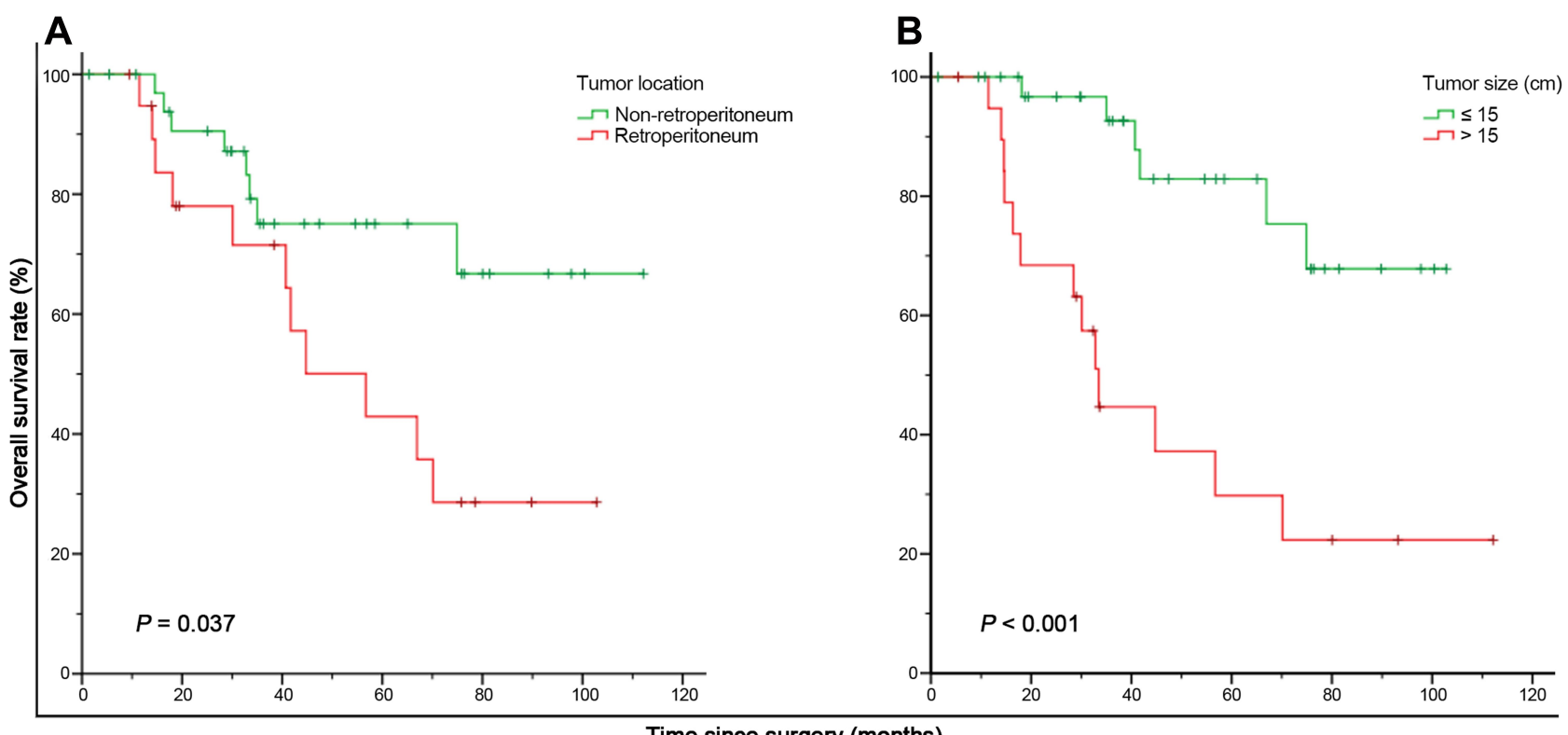

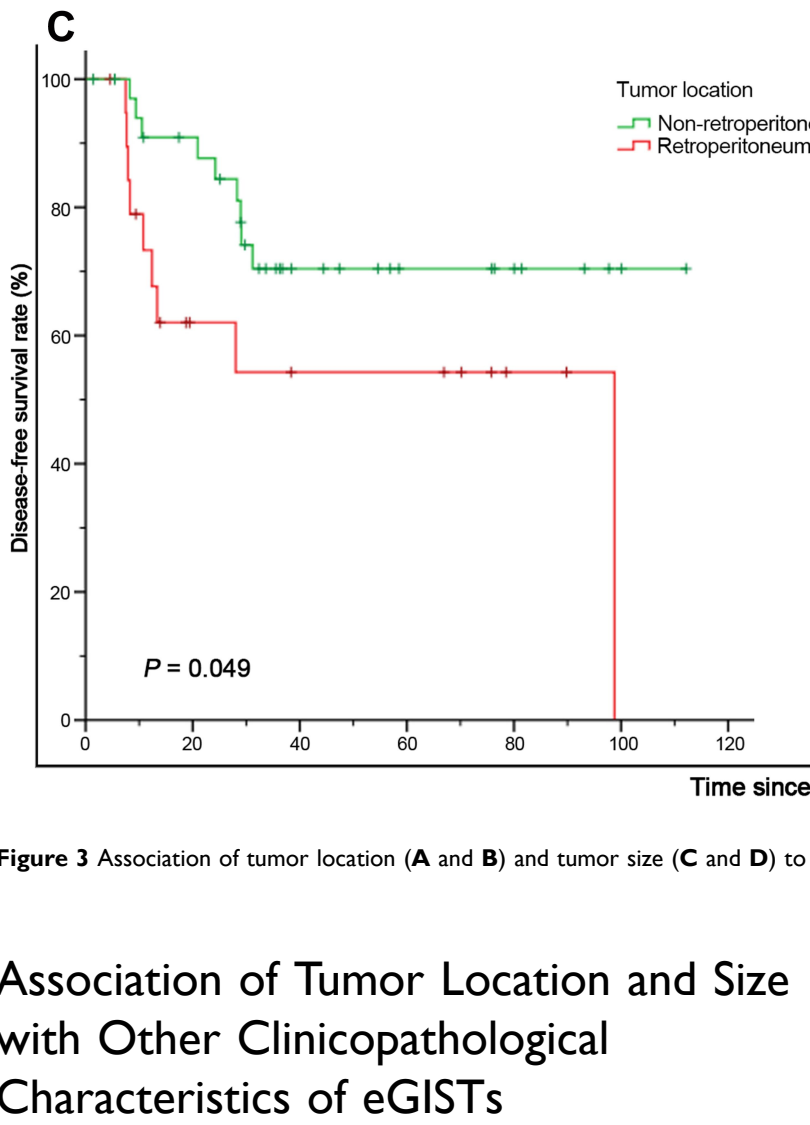

Table 4 illustrates the association between patients' characteristics of tumor location and size. Only age $(P=0.004)$ and mitotic count $(P=0.002)$ were found to be associated with tumor size, while none were found to be associated with tumor location.

Of note, no direct association between tumor size and location was found. However, when adjusted for survival outcomes (Figure 4), we found that eGISTs of size $\leq 15 \mathrm{~cm}$ located in the retroperitoneum had significantly better DFS as compared to those $>15 \mathrm{~cm}(P=0.006)$. Also, for nonretroperitoneum located eGISTs, those with tumors $\leq 15 \mathrm{~cm}$ were found to have a significantly better $\operatorname{OS}(P=0.020)$ and DFS $(P=0.023)$ as compared to tumors $>15 \mathrm{~cm}$. Further, despite that no significant difference in OS $(P=0.070)$ between the two tumor size groups of retroperitoneumlocated eGISTs were observed, our findings showed that when adjusted for mitotic count $>5 / 50$ HPFs (Figure 5), the 
Table 3 Incidence of Adverse Outcome (Tumor-Related Death or Recurrence) by Number of Risk Factors (RetroperitoneumLocated eGISTs and Size $>15 \mathrm{~cm}$ ) for eGIST Patients

\begin{tabular}{|l|l|l|l|l|l|l|}
\hline $\begin{array}{l}\text { No. of } \\
\text { Risk } \\
\text { Factors }\end{array}$ & $\begin{array}{l}\text { No. of Patients with } \\
\text { Death/Total in Group } \\
\text { (\%) }\end{array}$ & $\begin{array}{l}\text { Incidence of } \\
\text { Death per } \\
\text { Person-Year }\end{array}$ & $\mathbf{P}$ & $\begin{array}{l}\text { No. of Patients with } \\
\text { Recurrence/Total in Group } \\
\text { (\%) }\end{array}$ & $\begin{array}{l}\text { Incidence of } \\
\text { Recurrence per } \\
\text { Person-Year }\end{array}$ \\
\hline None & $2 / 22(9.1)$ & 0.02 & $0.019 *$ & $3 / 22(13.6)$ & 0.04 & $\begin{array}{l}\text { P } \\
\text { One }\end{array}$ I0/26(38.5) \\
Two & $7 / 7(100.0)$ & 0.10 & $0.007^{\#}$ & $10 / 26(38.5)$ & 0.11 & $0.054^{*}$ \\
$<0.001^{\%}$ & $5 / 7(71.4)$ & 0.49 & $0.008^{\%}$ \\
\hline
\end{tabular}

Notes: Incidence for eGIST = 0.10/y; * None vs One; \% None vs Two; \# One vs Two.

Abbreviation: eGISTs, extragastrointestinal stromal tumors.

significant difference in OS was indeed observed between those of tumor size $\leq 15$ or $>15 \mathrm{~cm}(P=0.043)$; but not for the other subgroups.

\section{Discussion}

Due to the rarity of eGISTs and to shed more light on this disease, we performed a multicentered study to assess their clinicopathological features and to identify their association with survival outcomes. A total of 55 cases were found eligible, of which most were found in the retroperitoneum and mesentery. Based on the modified NIH criteria, the majority of the eGISTs were classified as high risk. Multivariate analyses identified tumor location and size as independent factors for OS and DFS. KaplanMeier analyses showed that patients with tumors located in the retroperitoneum and of size $>15 \mathrm{~cm}$ had poorer OS and DFS compared to those non-retroperitoneum located tumors of size $\leq 15 \mathrm{~cm}$. Also, patients with 2 risk factors had a greater risk of tumor-related death and recurrence as compared to patients with no risk factors.

Till present, the exact origin and incidence of eGIST are still controversial. Many argue that they were either initially GISTs that were detached from the GI tract and got adhered outside the tract or are metastatic lesions of surgically undiagnosed GISTs that were not perioperatively located. In a study, ${ }^{17}$ the authors re-evaluated 14 cases of eGISTs and found that after carefully search for residual muscular tissue of the gut wall in the tumor pseudo capsule, 11 of the 14 cases were reclassified as GISTs with extramural growth or GISTs metastatic lesions. ${ }^{17}$ Despite such, there are still many cases of actual eGISTs reported. ${ }^{18-21}$ For this present study, the radiological imaging of all patients was carefully inspected for the presence of other lesions. Further, we included only cases in whom the abdomen was carefully evaluated perioperatively for additional lesions, apart from the eGISTs, for whom none were found. Also, on pathology, no microscopic residual attached muscular tissue of the gut wall was reported. Based on our analyses, the order of high occurrence of eGIST was the retroperitoneum (36.4\%), mesocolon (25.5\%), small bowel mesentery (12.7\%), abdominopelvic cavity (12.7\%), lesser omental sac $(5.5 \%)$, ovary $(3.6 \%)$, pancreatic capsule $(1.8 \%)$ and urinary bladder $(1.8 \%)$. The location order of high-occurrence was partly similar to the findings in the literature, ${ }^{22}$ who reported the retroperitoneum $(\mathrm{n}=4)$, mesentery $(\mathrm{n}=3)$, omentum $(\mathrm{n}=2)$ and pelvis $(\mathrm{n}=1)$ as their most commonly observed location of eGIST.

In terms of clinical characteristics, the findings of the present study differ from a literature review of 60 eGIST cases, ${ }^{23}$ in which the authors reported that the majority of the eGISTs occurred in females (57\%) and the mean age was 54 years old. In contrast with our study cohort, male (56.4\% vs $43.6 \%$ ) cases were predominant, and the mean age of tumor occurrence was 58 years old. We hypothesize that this may be related to population ethnicity, as in the analysis of previous study, ${ }^{23}$ among the eight studies investigated, only one ${ }^{24}$ was from China, and in that study, male cases were also predominant ( $60 \%$ vs $40 \%$ ) at a mean age of 60 years old, resonating to that of our findings. However, more studies are required to validate this hypothesis.

Most GISTs have positive IHC staining for KIT (CD117) (95\%) and CD 34 (70\%), which is important for asserting differential diagnosis from other mesenchymal tumors. ${ }^{25}$ Likewise, immunohistochemistry is essential for confirming the diagnosis of eGISTs. Findings from a retrospective analysis of a single institution ${ }^{12}$ showed that $95 \%$ (106/112 cases), $62 \%$ (53/86 cases), and 93\% (81/87 cases) of the eGIST patients were stained positive on IHC for CD117, CD34 and DOG-1, respectively. In a study, ${ }^{26}$ the authors found that $92.2 \%$ (47/51 cases), $80.6 \%$ (25/31 cases), and $100 \%$ (13/13 cases) of the patients had positive staining with CD117, CD34 and 
Table 4 Association of Clinicopathological Characteristics of eGIST Patients with Tumor Location and Tumor Size

\begin{tabular}{|c|c|c|c|c|c|c|}
\hline \multirow[t]{2}{*}{ Characteristics } & \multicolumn{2}{|l|}{ Tumor Location (n) } & \multirow[t]{2}{*}{$P$ value } & \multicolumn{2}{|c|}{ Tumor Size (n) } & \multirow[t]{2}{*}{$P$ value } \\
\hline & Retroperitoneum & Non-Retroperitoneum & & $\leq 15$ & $>15$ & \\
\hline Age (year) & & & 0.646 & & & 0.004 \\
\hline$\leq 58$ & 11 & 17 & & 23 & 5 & \\
\hline$>58$ & 9 & 18 & & 12 & 15 & \\
\hline Gender & & & 0.877 & & & 0.681 \\
\hline Male & II & 20 & & 19 & 12 & \\
\hline Female & 9 & 15 & & 16 & 8 & \\
\hline Tumor rupture & & & 0.057 & & & 0.057 \\
\hline Present & 2 & 0 & & 0 & 2 & \\
\hline Absent & 18 & 35 & & 35 & 18 & \\
\hline Tumor necrosis & & & 0.086 & & & 0.086 \\
\hline Present & 15 & 18 & & 18 & 15 & \\
\hline Absent & 5 & 17 & & 17 & 5 & \\
\hline Tumor location (categorized) & & & - & & & 0.874 \\
\hline Retroperitoneum & - & - & & 13 & 7 & \\
\hline Non-retroperitoneum & - & - & & 22 & 13 & \\
\hline Tumor size & & & 0.874 & & & - \\
\hline$(2$ categories) $(\mathrm{cm})$ & & & & & & \\
\hline$\leq 15$ & 13 & 22 & & - & - & \\
\hline$>15$ & 7 & 13 & & - & - & \\
\hline Mitotic count (/50 HPF) & & & 0.052 & & & 0.002 \\
\hline$\leq 5$ & 6 & 20 & & 22 & 4 & \\
\hline$>5$ & 14 & 15 & & 13 & 16 & \\
\hline Histopathological classification & & & 0.197 & & & 0.165 \\
\hline Spindle & 13 & 29 & & 29 & 13 & \\
\hline Epithelioid & 1 & 0 & & 1 & 0 & \\
\hline Mixed & 6 & 6 & & 5 & 7 & \\
\hline Postoperative complications & & & 0.095 & & & 0.095 \\
\hline Present & 3 & 1 & & 1 & 3 & \\
\hline Absent & 17 & 34 & & 34 & 17 & \\
\hline Adjuvant therapy & & & 0.672 & & & 0.874 \\
\hline Received & 8 & 12 & & 13 & 7 & \\
\hline Not received & 12 & 23 & & 22 & 13 & \\
\hline Modified NIH risk categories & & & 0.248 & & & 0.148 \\
\hline VLR & 0 & 2 & & 2 & 0 & \\
\hline LR & 0 & 3 & & 3 & 0 & \\
\hline $\mathbb{I R}$ & 2 & I & & 3 & 0 & \\
\hline $\mathrm{HR}$ & 18 & 29 & & 27 & 20 & \\
\hline
\end{tabular}

Abbreviations: eGISTs, extragastrointestinal stromal tumors; HPF, high-power field; VLR, very low risk; LR, low risk; IR, intermediate risk; HR, high risk.

DOG-1, respectively, on IHC from multi-institutional data collected in South Korea. Although our data did not show such high positivity of these markers, however, our findings did show that eGISTs had high expression of CD117 (78.2\%), CD 34 (70.9\%), and DOG-1 (62.2\%); thereby in accordance to the literature showing similarities of high expression of these markers in eGISTs; and also validating the close association between eGISTs and GISTs. Due to these similarities, it was thereby considered that the treatment of eGISTs would be similar to GISTs. 

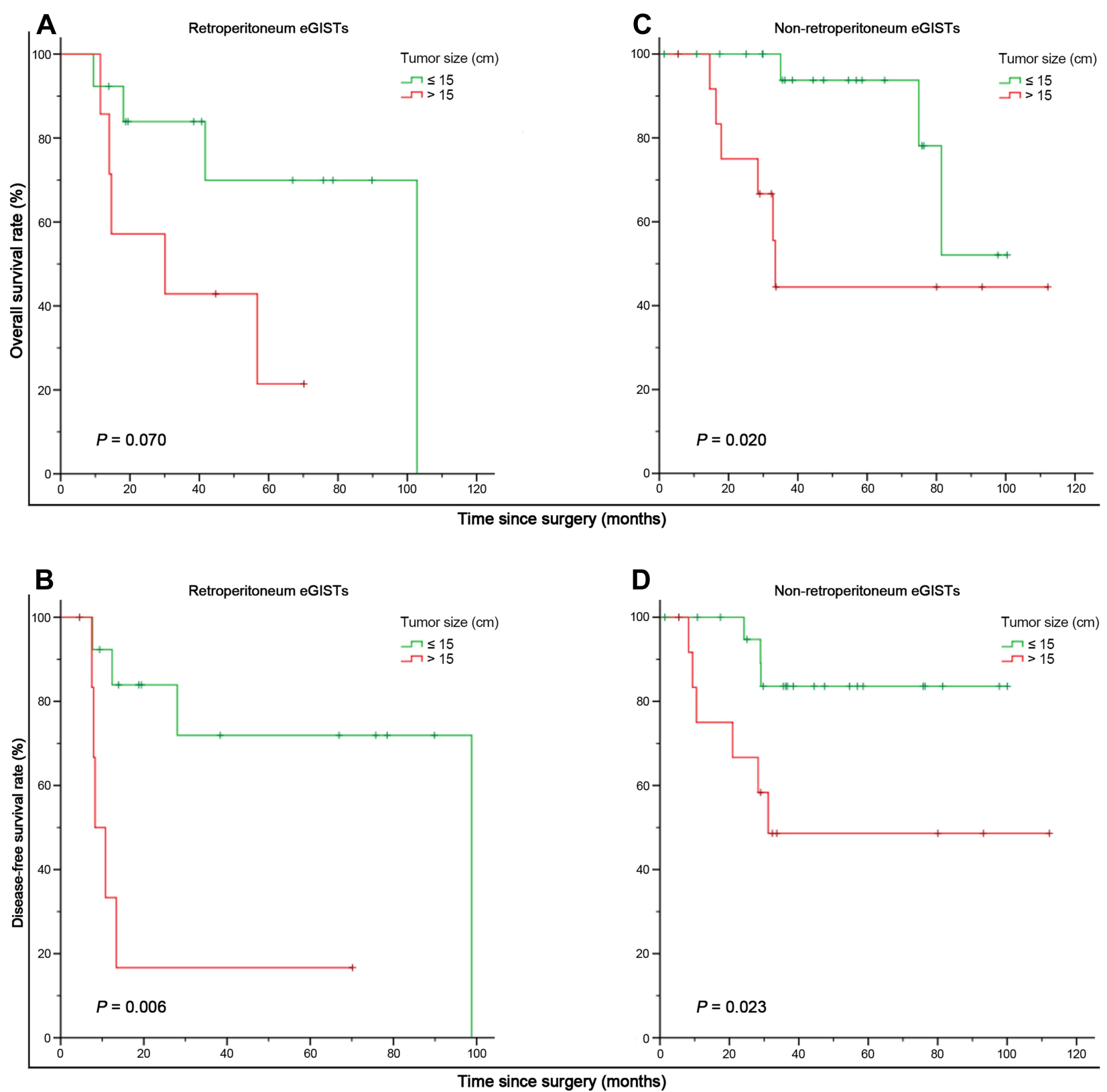

Figure 4 Association of retroperitoneum-located eGISTs (A and B) and non-retroperitoneum-located eGISTs (C and D) of different tumor size to overall survival and disease-free survival.

Abbreviation: eGISTs, extragastrointestinal stromal tumors.

It has been observed that eGISTs were also responsive to tyrosine kinase inhibitors (TKIs). Therefore, the recognition of KIT and PDGFRA mutations is important for further validating an eGIST diagnosis due to their controversial localization but most importantly, for predicting their response to treatment. In the present study, we found that $76.5 \%$ of the cases were positive for $K I T$ exon $11(\mathrm{n}=13)$ mutations, $33.3 \%$ for KIT exon 9 mutations while none were positive for KIT exon 13 and 17 mutations. In GISTs clinical trials, it was found that the presence of KIT exon 11 mutation was associated with better response rate, progression-free survival (PFS) and OS as compared to those with KIT exon 9 or wild-type GISTs. Comparatively, till present, there has been a lack of large case studies for evaluating the actual relevance of TKI in eGISTs. In a study, ${ }^{26}$ despite having obtained data from 7 institutions across South Korea, the authors could only calculate the recurrence-free survival (RFS) on 13 eGISTs cases who received adjuvant imatinib (60.1 months) but not for the 18 patients who did not receive 

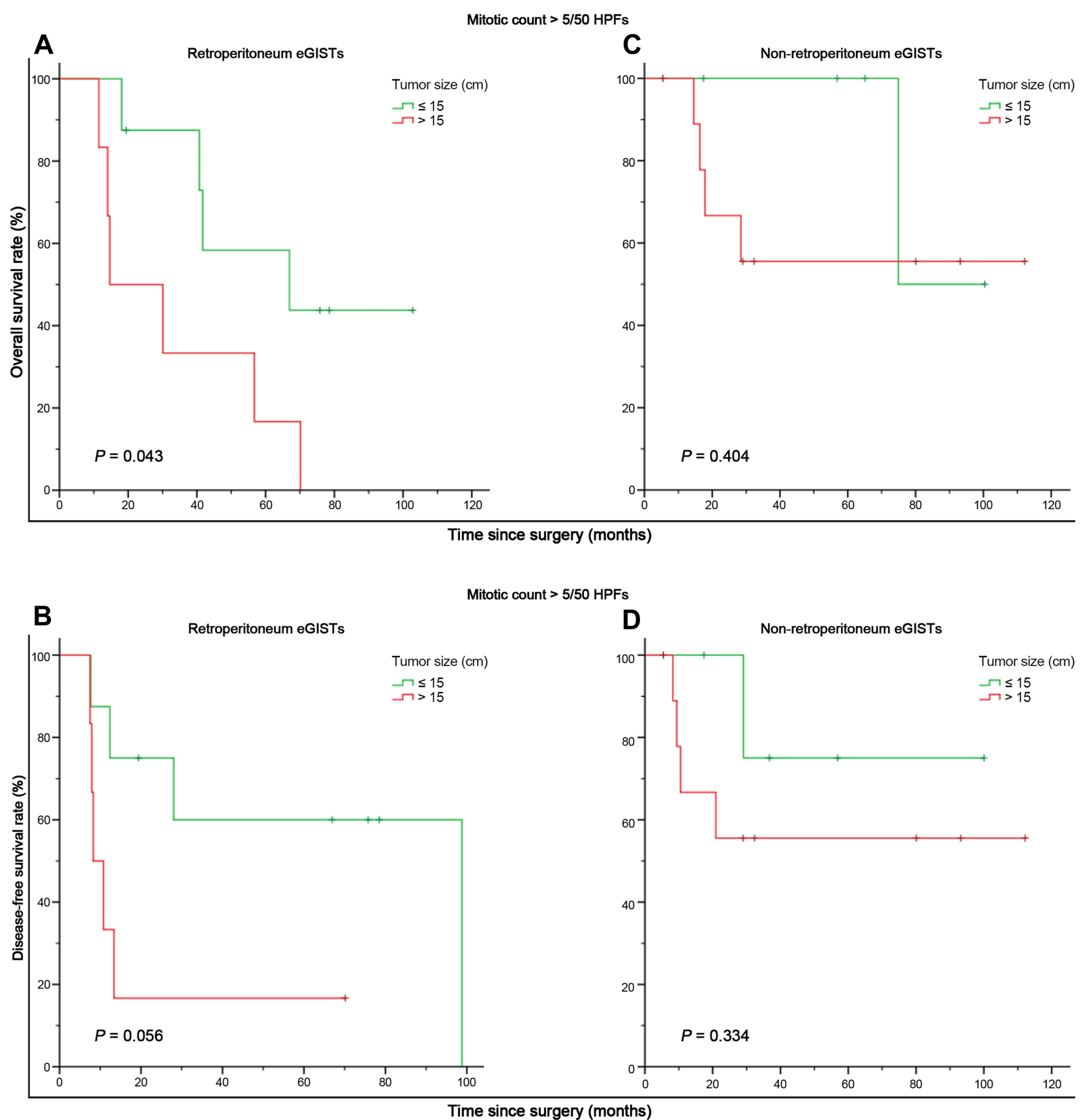

Figure 5 Association of retroperitoneum-located eGISTs (A and $\mathbf{B})$ and non-retroperitoneum-located eGISTs (C and $\mathbf{D})$ of different tumor size to overall survival and disease-free survival, after adjusting for mitotic count $>5 / 50$ HPFs.

Abbreviations: eGISTs, extragastrointestinal stromal tumors; HPF, high-power field.

imatinib due to the small number of recurrence $(\mathrm{n}=2)$. In this present study, 24 cases underwent genetic testing, but only 13 had KIT exon 11 mutations. Of them, only 6 had adjuvant imatinib therapy, and the number of registered recurrence $(\mathrm{n}=2)$ and death $(\mathrm{n}=2)$ was similar in both groups who had and did not have imatinib. Of the 11 cases that did not have KIT exon 11 mutations, only 3 had adjuvant imatinib therapy, and the number of registered recurrences was 1 in both groups and the only death observed was in the group that did not have imatinib. In contrast, there have been reported case reports suggesting the regression of eGIST after using imatinib. ${ }^{27-31}$ However, no valid conclusion can be drawn on the efficacy of imatinib in the treatment of eGISTs due to a limited number of reported cases, low compliance to long-term treatment, and absence of comparative arm 
analyses. The lack of compliance to TKI prescription may be summarized to the expensive cost of imatinib (during the study period) ${ }^{32,33}$ low awareness on the treatment of GISTs, ${ }^{34}$ and poor adherence to long-term treatment which is often associated with increased risk of side-effects of the drugs. ${ }^{35}$ Further, due to the rarity of this disease, we believe a wide interinstitutional and multi-country collaboration would be needed to first, demystify the localization of eGISTs and second, to properly assess the actual efficacy of imatinib in eGISTs.

However, despite the similarities in IHC and genetic testing between eGISTs and GISTs, the prognoses of eGISTs are less favorable compared to GISTs as the former tends to have higher proliferative mitotic indices (GISTs vs eGISTs, median range, 4-8/50 $\mathrm{HPF}^{36-38}$ vs $10-15 / 50$ $\mathrm{HPF}^{12,39,40}$ ), larger tumor size (GISTs vs eGISTs, median range, $4-7 \mathrm{~cm}^{38,41,42}$ vs $7.5-15 \mathrm{~cm}^{12,14,39,40,43}$ ) and greater risk to recurrence or distant metastasis. ${ }^{14,44}$ Similarly, our findings showed that the median tumor size $(13 \mathrm{~cm}$, range, 0.4-29 cm) and mitotic value (13 HPF, range, 0-50 HPF) were in accordance with that of reported literature. In addition, we further observed that the recurrences most commonly occurred in cases graded as stage 4 (modified NIH criteria), and in those patients who had particularly large tumors (mean, $14.7 \mathrm{~cm}, \mathrm{~S} . \mathrm{D} \pm 6.9 \mathrm{~cm}$ ) and high mitotic value (mean, 13.4 HPF, S.D \pm 14.9). This may be explained by the fact that since eGISTs develop outside the GI tract, but still depending on their specific localization, in their early-stage, their growth may not affect the neighboring vascular or organ function to an extent for causing symptoms, may not be felt and thereby remain undiagnosed. However, by the time they become symptomatic, their size has already multiplied and developed into an advancedstage lesion; it has histologically become more cellular, with more nuclear atypia and pleomorphism, and clinically more aggressive (higher mitotic rates). Subsequently, this renders clinical management difficult, possibly losing their chance for surgical resection and leading to poor survival outcomes. This further clarifies our findings which suggested that, first, tumors located in the retroperitoneum and size $>15 \mathrm{~cm}$ were independent factor affecting survival as such tumors have more space to develop to an advanced/ aggressive stage with a lower chance of being symptomatic and second, that patients with the greater number of adverse factors had a greater risk of adverse outcomes.

Further, we should highlight that despite the modified NIH criteria consider tumor size and mitotic rate as important risk factors; the mitotic rate was not found as an independent risk factor for prognostication of survival outcomes. However, the importance of mitotic rate should not be neglected. As illustrated in Figure 4A, despite no significant difference in OS were found between retroperitoneumlocated eGISTs of size $\leq 15$ or $>15 \mathrm{~cm}$, when adjusted for mitotic count $>5 / 50 \mathrm{HPFs}$, tumors of size $\leq 15$ were found to have significantly superior OS as compared to those $>15 \mathrm{~cm}$ (Figure 5A) $(P=0.043)$. However, a mitotic count $>5 / 50$ HPFs did not show any significant impact for the other subgroups. These findings highlight the complex nature of eGISTs and a call for larger multicentered prospective studies despite that we hypothesized that this lack of statistical significance might have been due to the limited number of investigated cases.

This present study was designed to assess the clinicopathological characteristics of eGISTs and to identify factors that would affect survival. Despite the important findings reported, several shortcomings should be addressed. First, although being a multicenter study, one of the greatest limitations has been the limited number of retrievable cases due to the low incidence of eGISTs, $\sim 5 \%$ of all GISTs. This may have affected the findings to a certain extent. Also, second, even though no residual gut wall tissues were found in the pathological report of the investigated cases, we should not neglect the possibility of the presence of such tissues outside the microscopy regions, or that they may have been weaned off during the tumor growth. Third, several other factors, such as correlation with Ki-67, the radicality of surgeries, postoperative complications, and more that may have impacted the patients' survival and could not be fully analyzed due to the retrospective nature of this study and incomplete data recordings in the registries despite attempts to recontact the patients and their relatives. As such, the findings of this study should be carefully interpreted.

\section{Conclusion}

In summary, our data showed that eGIST most commonly occurred in the retroperitoneum, and the majorities were classified as high risk based on the NIH criteria. eGISTs located in the retroperitoneum and of size $>15 \mathrm{~cm}$ had the poorer OS and DFS compared to those in the non-retroperitoneum and $<15 \mathrm{~cm}$. Further, patients with two risk factors had worse overall survival outcomes compared to those no risk factors.

\section{Data Sharing Statement}

The data for this work can be provided upon reasonable requests to the corresponding authors. 


\section{Ethics Approval and Consent to Participate}

The study was approved by the research ethics committee of Guangdong Provincial People's Hospital and was performed in accordance with the standards of the Declaration of Helsinki. Patients admitted to the hospital have signed informed consent forms stating that clinical data during hospitalization can be used for anonymous retrospective studies, and it has been approved by the hospital ethics committee. Each institution of this study was performed following the standards of the Declaration of Helsinki. All patients were contacted by outpatient surveillance or telephone by their hospitals specifically during follow-up. Informed consent was obtained to confirm that they willing to be followed up.

\section{Acknowledgments}

We thank all the related staff of all cooperating institutions and the patients and relatives for their support in data sharing for performing this study.

\section{Author Contributions}

All authors made substantial contributions to conception and design, acquisition of data, or analysis and interpretation of data; took part in drafting the article or revising it critically for important intellectual content; agreed to submit to the current journal; gave final approval of the version to be published; and agree to be accountable for all aspects of the work. Contributed equally to this manuscript: Weixian $\mathrm{Hu}$ and Chengbin Zheng.

\section{Funding}

This work was supported by the Supporting Scientific Research Fund of Outstanding Young Medical Talents of Guangdong Province, Guangdong Provincial People's Hospital (Grant number: KJ012019439), the Wu Jieping Medical Foundation (201909), and the Medical Scientific Research Foundation of Guangdong Province (A2019165).

\section{Disclosure}

All authors declare no conflicts-of-interest related to this article.

\section{References}

1. Soreide K, Sandvik OM, Soreide JA, Giljaca V, Jureckova A, Bulusu VR. Global epidemiology of gastrointestinal stromal tumours (GIST): a systematic review of population-based cohort studies. Cancer Epidemiol. 2016;40:39-46. doi:10.1016/j.canep.2015.10.031

2. Demetri GD, von Mehren M, Blanke CD, et al. Efficacy and safety of imatinib mesylate in advanced gastrointestinal stromal tumors. $N$ Engl $J$ Med. 2002;347(7):472-480. doi:10.1056/NEJMoa020461
3. Valsangkar N, Sehdev A, Misra S, Zimmers TA, O'Neil BH, Koniaris LG. Current management of gastrointestinal stromal tumors: surgery, current biomarkers, mutations, and therapy. Surgery. 2015;158(5):1149-1164. doi:10.1016/j.surg.2015.06.027

4. Heinrich MC, Corless CL, Duensing A, et al. PDGFRA activating mutations in gastrointestinal stromal tumors. Science. 2003;299 (5607):708-710. doi:10.1126/science.1079666

5. Hirota S, Isozaki K, Moriyama Y, et al. Gain-of-function mutations of c-kit in human gastrointestinal stromal tumors. Science. 1998;279 (5350):577-580. doi:10.1126/science.279.5350.577

6. Gold JS, Gönen M, Gutiérrez A, et al. Development and validation of a prognostic nomogram for recurrence-free survival after complete surgical resection of localised primary gastrointestinal stromal tumour: a retrospective analysis. Lancet Oncol. 2009;10 (11):1045-1052. doi:10.1016/S1470-2045(09)70242-6

7. Ma GL, Murphy JD, Martinez ME, Sicklick JK. Epidemiology of gastrointestinal stromal tumors in the era of histology codes: results of a population-based study. Cancer Epidemiol Biomark Prev. 2015;24(1):298-302. doi:10.1158/1055-9965.EPI-14-1002

8. Joensuu H, Vehtari A, Riihimäki J, et al. Risk of recurrence of gastrointestinal stromal tumour after surgery: an analysis of pooled population-based cohorts. Lancet Oncol. 2012;13(3):265-274. doi:10.1016/S1470-2045(11)70299-6

9. Miettinen M, Lasota J. Gastrointestinal stromal tumors: pathology and prognosis at different sites. Semin Diagn Pathol. 2006;23 (2):70-83. doi:10.1053/j.semdp.2006.09.001

10. Martin SA, Sears DL, Sebo TJ, Lohse CM, Cheville JC. Smooth muscle neoplasms of the urinary bladder: a clinicopathologic comparison of leiomyoma and leiomyosarcoma. Am J Surg Pathol. 2002;26(3):292-300. doi:10.1097/00000478-200203000-00002

11. Miettinen M, Monihan JM, Sarlomo-Rikala M, et al. Gastrointestinal stromal tumors/smooth muscle tumors (GISTs) primary in the omentum and mesentery: clinicopathologic and immunohistochemical study of 26 cases. Am J Surg Pathol. 1999;23(9):1109-1118. doi:10.1097/00000478-199909000-00015

12. Miettinen M, Felisiak-Golabek A, Wang Z, Inaguma S, Lasota J. GIST manifesting as a retroperitoneal tumor: clinicopathologic immunohistochemical, and molecular genetic study of 112 cases. Am J Surg Pathol. 2017;41(5):577-585. doi:10.1097/PAS.0000000000000807

13. Emory TS, Sobin LH, Lukes L, Lee DH, O'Leary TJ. Prognosis of gastrointestinal smooth-muscle (stromal) tumors: dependence on anatomic site. Am J Surg Pathol. 1999;23(1):82-87. doi:10.1097/ 00000478-199901000-00009

14. Reith JD, Goldblum JR, Lyles RH, Weiss SW. Extragastrointestinal (soft tissue) stromal tumors: an analysis of 48 cases with emphasis on histologic predictors of outcome. Mod Pathol. 2000;13(5):577-585. doi:10.1038/modpathol.3880099

15. Joensuu H. Risk stratification of patients diagnosed with gastrointestinal stromal tumor. Hum Pathol. 2008;39(10):1411-1419. doi:10.1016/j.humpath.2008.06.025

16. Jones RL. Practical aspects of risk assessment in gastrointestinal stromal tumors. J Gastrointest Cancer. 2014;45(3):262-267. doi:10.1007/s12029-014-9615-x

17. Agaimy A, Wunsch PH. Gastrointestinal stromal tumours: a regular origin in the muscularis propria, but an extremely diverse gross presentation. A review of 200 cases to critically re-evaluate the concept of so-called extra-gastrointestinal stromal tumours. Langenbecks Arch Surg. 2006;391(4):322-329. doi:10.1007/s00423-005-0005-5

18. Acar T, Efe D, Okus A, Ocal I, Harman M. A rare solid tumor of the retroperitoneum with venous extension and lung metastasis: extra-gastrointestinal stromal tumor. Turk J Gastroenterol. 2015;26 (4):358-359. doi:10.5152/tjg.2015.0149

19. Kalogeraki A, Tamiolakis D, Papadakis M, Moustou E, Datseri G, Tzardi M. Abdominal primary extra-gastrointestinal stromal tumor (E-GIST). A cytologic diagnosis in ascitic fluid. Rev Esp Enferm Dig. 2015;107(8):516-518. doi:10.17235/reed.2015.3598/2014 
20. Laroia ST, Yadav T, Rastogi A, Sarin S. Malignant retroperitoneal extra-gastrointestinal stromal tumor: a unique entity. World J Oncol. 2016;7(2-3):45-50. doi:10.14740/wjon926w

21. Divakaran J, Chander B. Primary extra-gastrointestinal stromal tumor of the omentum. $J$ Cancer Res Ther. 2012;8(3):433-435. doi:10.4103/0973-1482.103527

22. Patnayak R, Jena A, Parthasarathy S, et al. Primary extragastrointestinal stromal tumors: a clinicopathological and immunohistochemical study - a tertiary care center experience. Indian J Cancer. 2013;50 (1):41-45. doi:10.4103/0019-509X.112298

23. Apostolou KG, Schizas D, Vavouraki E, et al. Clinicopathological and molecular factors, risk factors, treatment outcomes and risk of recurrence in mesenteric and retroperitoneal extragastrointestinal stromal tumors. Anticancer Res. 2018;38(4):1903-1909.

24. Zheng S, Huang KE, Tao DY, Pan YL. Gene mutations and prognostic factors analysis in extragastrointestinal stromal tumor of a Chinese three-center study. J Gastrointest Surg. 2011;15 (4):675-681. doi:10.1007/s11605-010-1292-x

25. Miettinen M, Lasota J. Gastrointestinal stromal tumors: review on morphology, molecular pathology, prognosis, and differential diagnosis. Arch Pathol Lab Med. 2006;130(10):1466-1478.

26. Yi JH, Park BB, Kang JH, et al. Retrospective analysis of extra-gastrointestinal stromal tumors. World $J$ Gastroenterol. 2015;21(6):1845-1850. doi:10.3748/wjg.v21.i6.1845

27. Alabed YZ. Gastrointestinal stromal tumor of the prostate: staging and evaluation of response to therapy with $18 \mathrm{~F}-\mathrm{FDG}$ PET/CT. Clin Nucl Med. 2018;43(1):52-54. doi:10.1097/RLU.0000000000001906

28. Barros A, Linhares E, Valadao M, et al. Extragastrointestinal stromal tumors (EGIST): a series of case reports. Hepatogastroenterology. 2011;58(107-108):865-868.

29. Foster R, Solano S, Mahoney J, Fuller A, Oliva E, Seiden MV. Reclassification of a tubal leiomyosarcoma as an eGIST by molecular evaluation of c-KIT. Gynecol Oncol. 2006;101(2):363-366. doi:10.1016/j.ygyno.2005.12.022

30. Li H, Li J, Li X, Kang Y, Wei Q. An unexpected but interesting response to a novel therapy for malignant extragastrointestinal stromal tumor of the mesoileum: a case report and review of the literature. World J Surg Oncol. 2013;11(1):174. doi:10.1186/1477-7819-11-174

31. Muto M, Fujiya M, Okada T, Inoue M, Yabuki H, Kohgo Y. An invasive extragastrointestinal stromal tumor curably resected following imatinib treatment. J Gastrointestin Liver Dis. 2013;22(3):329-332.

32. Sheng G, Chen S, Dong C, et al. Societal implications of medical insurance coverage for imatinib as first-line treatment of chronic myeloid leukemia in China: a cost-effectiveness analysis. $\mathrm{J} \mathrm{Med}$ Econ. 2017;20(4):371-381. doi:10.1080/13696998.2016.1271336

33. Wu B, Liu M, Li T, Lin H, Zhong H. An economic analysis of high-dose imatinib, dasatinib, and nilotinib for imatinib-resistant chronic phase chronic myeloid leukemia in China: a CHEERS-compliant article. Medicine (Baltimore). 2017;96(29):e7445. doi:10.1097/MD.00000000 00007445
34. Bartholomew AJ, Dohnalek H, Prins PA, et al. Underuse of exon mutational analysis for gastrointestinal stromal tumors. J Surg Res. 2018;231:43-48. doi:10.1016/j.jss.2018.05.014

35. Sodergren SC, White A, Efficace F, et al. Systematic review of the side effects associated with tyrosine kinase inhibitors used in the treatment of gastrointestinal stromal tumours on behalf of the EORTC Quality of Life Group. Crit Rev Oncol Hematol. 2014;91(1):35-46. doi:10.1016/ j.critrevonc.2014.01.002

36. Joensuu H, Wardelmann E, Sihto H, et al. Effect of KIT and PDGFRA mutations on survival in patients with gastrointestinal stromal tumors treated with adjuvant imatinib: an exploratory analysis of a randomized clinical trial. JAMA Oncol. 2017;3(5):602-609. doi:10.1001/jamaoncol.2016.5751

37. Wada N, Kurokawa Y, Nishida T, et al. Subgroups of patients with very large gastrointestinal stromal tumors with distinct prognoses: a multicenter study. J Surg Oncol. 2014;109(2):67-70. doi:10.1002/jso.23471

38. Wozniak A, Rutkowski P, Schoffski P, et al. Tumor genotype is an independent prognostic factor in primary gastrointestinal stromal tumors of gastric origin: a european multicenter analysis based on ConticaGIST. Clin Cancer Res. 2014;20(23):6105-6116. doi:10.1158/1078-0432.CCR-14-1677

39. Lam MM, Corless CL, Goldblum JR, Heinrich MC, Downs-Kelly E, Rubin BP. Extragastrointestinal stromal tumors presenting as vulvovaginal/rectovaginal septal masses: a diagnostic pitfall. Int J Gynecol Pathol. 2006;25(3):288-292. doi:10.1097/01.pgp.0000215291.22867. 18

40. Kim KH, Nelson SD, Kim DH, et al. Diagnostic relevance of overexpressions of PKC-theta and DOG-1 and KIT/PDGFRA gene mutations in extragastrointestinal stromal tumors: a Korean six-centers study of 28 cases. Anticancer Res. 2012;32(3):923-937.

41. Biasco G, Velo D, Angriman I, et al. Gastrointestinal stromal tumors: report of an audit and review of the literature. Eur J Cancer Prev. 2009;18(2):106-116. doi:10.1097/CEJ.0b013e328 $30 \mathrm{c} 8 \mathrm{da} 8$

42. Kim MC, Yook JH, Yang HK, et al. Long-term surgical outcome of 1057 gastric GISTs according to 7th UICC/AJCC TNM system: multicenter observational study from Korea and Japan. Medicine (Baltimore). 2015;94(41):e1526. doi:10.1097/MD.0000000000001526

43. Dedemadi G, Georgoulis G, Kontopanos D, et al. Extragastrointestinal stromal tumors of the omentum: review apropos of a case with a novel gain-of-function KIT mutation. J Gastrointest Cancer. 2009;40(3-4):73-78. doi:10.1007/s12029-009-9089-4

44. Du CY, Shi YQ, Zhou Y, Fu H, Zhao G. The analysis of status and clinical implication of KIT and PDGFRA mutations in gastrointestinal stromal tumor (GIST). J Surg Oncol. 2008;98(3):175-178. doi: $10.1002 /$ jso. 21104

\section{Publish your work in this journal}

Cancer Management and Research is an international, peer-reviewed open access journal focusing on cancer research and the optimal use of preventative and integrated treatment interventions to achieve improved outcomes, enhanced survival and quality of life for the cancer patient.
The manuscript management system is completely online and includes a very quick and fair peer-review system, which is all easy to use. Visit http://www.dovepress.com/testimonials.php to read real quotes from published authors. 